\title{
Perinatal exposure to 5-metoxytryptamine, behavioural-stress reactivity and functional response of 5-HT1A receptors in the adolescent rat
}

\author{
C. Cannizzaro*, F. Plescia, M. Gagliano, G. Cannizzaro, G. Mantia, \\ M. La Barbera, G. Provenzano, E. Cannizzaro \\ Dipartimento di Scienze Farmacologiche, Università di Palermo, V. Vespro 129, 90127 Palermo, Italy
}

Received 7 May 2007; received in revised form 27 July 2007; accepted 30 July 2007

Available online 2 August 2007

\begin{abstract}
Serotonin is involved in a wide range of physiological and patho-physiological mechanisms. In particular, 5-HT1A receptors are proposed to mediate stress-adaptation. The aim of this research was to investigate in adolescent rats: first, the consequences of perinatal exposure to 5metoxytryptamine (5MT), a 5-HT1/5-HT2 serotonergic agonist, on behavioural-stress reactivity in elevated plus maze, open field and forced swim tests; secondly, whether the behavioural effects induced by perinatal exposure to 5MT on open field and forced swim tests were affected by the selective 5-HT1A receptor agonist LY 228729, a compound able to elicit a characteristic set of motor behaviours on these experimental models, and by the co-administration of the selective and silent 5-HT1A antagonist WAY 100635. Results indicate that a single daily injection of 5MT to, pregnant dams from gestational days 12 to 21 ( $1 \mathrm{mg} / \mathrm{kg} \mathrm{s.c.)}$, and to the pups from postnatal days 2 to 18 ( $0.5 \mathrm{mg} \mathrm{kg}$ s.c.), induce in the adolescent rat offspring: an increase in the percentage of entries and time spent on the open arms in the elevated plus maze; a reduction in locomotor activity and rearing frequency, and an increase in the time spent on the central areas in the open field test; a decrease in immobility and an increase in swimming in the forced swim test. Acute administration of LY $228729(1.5 \mathrm{mg} / \mathrm{kg}$ s.c.) strongly decreases rearing frequency and increases peripheral activity in the open field test, and decreases immobility and increases swimming in the forced swim test both in perinatally vehicle and 5MT-exposed offspring. Co-administration of WAY $100635(0.25 \mathrm{mg} / \mathrm{kg}$ s.c.) abolishes the effects exerted by LY 228729 . These results suggest that, in the adolescent rat, perinatal exposure to 5MT enhances the stress-related adaptive behavioural responses, presumably through a predominant action on presynaptic 5-HT1A receptors and does not deteriorate the functional response of 5-HT1A receptors to selective agonist and antagonist compounds. (C) 2007 Elsevier B.V. All rights reserved.
\end{abstract}

Keywords: Perinatal 5MT; 5-HT1A receptors; Acute LY 228729 and WAY 100635; Behavioural-stress reactivity; Adolescent rat

\section{Introduction}

Serotonin exerts its influence in a number of behavioural and physiological processes in adult mammals $[1,34,46,60]$. Of the multiple types of receptors for serotonin present in the brain, in particular, 5-HT1A receptors are proposed to mediate stressadaptation [47] and a dysregulation of 5-HT1A receptors is implicated in changes of the emotional state $[4,7,8]$. Drugs with high affinity for 5-HT1A receptors are therapeutically effective agents for treatment of clinical syndromes related to stress, including anxiety [3].

Considerable evidence, from both in vivo and in vitro studies, indicate that serotonin, during brain development, plays a criti-

\footnotetext{
* Corresponding author. Tel.: +39091 6553215; fax: +39 091591063.

E-mail address: psycho@unipa.it (C. Cannizzaro).
}

cal role in formulating the maturation of its target cells, prior to the time it assumes its role as a neurotransmitter in the mature brain $[2,41,42,50,62,65]$. Serotonin receptors, expressed during the embriogenic period, include the 5-HT1A receptor subtype which, through an inhibitory auto-regulation, likely mediates some of these developmental effects [50,66,68]. Exposure during perinatal neurogenesis to drugs that modify the levels of serotonin or stimulate 5-HT1A receptors, interfering with the role of serotonin, produces long-lasting consequences on development, morphology, function and neural organization of the adult rat brain $[43,48,63,67,69]$. One of the serotonin agonists often used to investigate the functionality of 5-HT1A receptors during the ontogenetic brain development in the rat, is 5-methoxytryptamine (5MT), a general 5-HT1/5-HT2 agonist [64,67]. 5MT has been reported to inhibit serotonin terminal growth [56] and to reduce the expression of 5-HT1A receptor transcripts throughout the brain in neonatal rat offspring 
$[43,62]$. Moreover, rat pups exposed through gestation and during the early neonatal period to 5MT, show several behavioural changes, such as hypersensitivity of sensory-motor functions, that reflect variations in the brain serotonergic transmission $[38,56]$. However, consequences of perinatal exposure to 5MT on rat emotionality are still conflicting: indeed, both diminished anxiety-like behaviour and increased fear-conditioning potentiation, have been reported in rat pups [66,67].

Based upon these findings, the aim of this study was to better characterize the effects exerted by the perinatal exposure to 5MT on behavioural-stress reactivity in adolescent male rats. Adolescence was chosen since it represents an ontogenetic phase characterized by elevated basal levels of behavioural activation $[15,57]$. Behavioural-stress reactivity was investigated using the elevated plus maze and the open field tests, two well-validated unconditioned "state anxiety" models in rats $[33,37,45,46,54]$, and a single exposure to the forced swim test, which allows to evaluate the anxiety- and stress-related behaviour in the rat $[11,34,40]$. Forced swim was employed as far as swimming is a stressful situation the rat might encounter in nature and includes both psychological (novelty and water) and physiological (exercise and temperature) challenges [18].

When rats are treated with selective 5-HT1A receptor agonists they show a characteristic set of motor behaviours easily recognized and quantified, as increased locomotor activity, decreased rearing frequency and randomly circling in the periphery of the arena in the open field test $[13,20,33,35]$. Furthermore, 5-HT1A agonists, unlike noradrenergic and dopaminergic agents, selectively increase swimming in the forced swim test [23,46,53]. Among 5-HT1A receptor agonists, LY 228729, a tryptamine derivate, possesses high selectivity for 5-HT1A receptors $[10,26,27]$. Owing to the differences between presynaptic and postsynaptic 5-HT1A receptor populations (in terms of receptor reserve and receptor-effector coupling), several 5-HT1A antagonists of postsynaptic receptors could act as partial agonists at presynaptic receptors; WAY 100635, appears to be the first and highly selective and silent 5-HT1A receptor antagonist that abolishes the behavioural and electrophysiological effects produced by selective 5-HT1A agonists $[14,16,22,28,47,55]$. Therefore, in an attempt to determine whether perinatal exposure to 5MT may affect the functional response of 5-HT1A receptors, in the second part of this study we tested the effects of the acute administration of LY 228729 and its co-administration with WAY 100635 on the occurrence of the characteristic behavioural patterns induced by 5MT in the open field and forced swim tests, as a prove of the functional state of 5-HT1A receptors.

\section{Materials and methods}

\subsection{Animals and pharmacological treatments}

Wistar rats (Harlan, Udine, Italy) housed with free access to food and water were maintained on a $12 \mathrm{~h}$ on/off cycle $(8: 00-20: 00 \mathrm{~h})$ at a constant temperature $\left(22 \pm 2{ }^{\circ} \mathrm{C}\right)$ and humidity $(55 \pm 10 \%)$. Pairs of primiparous females of 120 days of age were mated with one male of 150 days of age. The day on which sperm was detected in the vagina smear was designed as gestation day (GD) 1 .
Pregnancy was determined by weighing and palpation. Ten days before delivery, pregnant dams were individually housed in sawdust-containing plastic rat cages $(40 \mathrm{~cm} \times 60 \mathrm{~cm}, 20 \mathrm{~cm}$ in height) and randomly assigned to the gestational pharmacological exposure.

Perinatal exposure to vehicle or 5MT was designed as follows: pregnant dams received a single daily injection of vehicle or $5 \mathrm{MT}(1 \mathrm{mg} / \mathrm{kg}$ s.c. $)$ over GD 12-21, because at this time 5-HT1A receptors appear in the fetal brain. All litters born within a 2-day period were reduced to eight pups (four males and four females), and maintained under standard laboratory conditions. Two days after birth, male offspring received a daily injection of vehicle or $5 \mathrm{MT}(0.5 \mathrm{mg} / \mathrm{kg}$ s.c.) from postnatal day (PND) 2 until PND 18, period in which 5-HT1A receptors reach their maturation [66]. The dosage in the pups was reduced in order to minimize possible adverse neurotoxic effects due to their immature metabolic systems. Immediately after birth and at weaning time, no significant differences in number, morbidity, mortality or weight were observed between the perinatally vehicle- and the perinatally 5MT-exposed offspring. On weaning time (PND 24), according to the perinatal exposure and the postnatal acute treatments, male pups were randomly assigned to the following eight experimental groups $(n=8)$ : perinatal vehicle + saline, perinatal vehicle + LY 228729, perinatal vehicle + WAY 100635, perinatal vehicle + LY 228729 + WAY 100635; perinatal 5MT + saline, perinatal $5 \mathrm{MT}+\mathrm{LY} 228729$, perinatal $5 \mathrm{MT}+\mathrm{WAY} 100635$, perinatal $5 \mathrm{MT}+\mathrm{LY}$ $228729+$ WAY 100635

At PND 42, LY 228729 at the dose of $1.5 \mathrm{mg} / \mathrm{kg}$, and WAY 100635 at the dose of $0.25 \mathrm{mg} / \mathrm{kg}$, were acutely administered respectively 50 and $60 \mathrm{~min}$ before the experimental sessions. The dose of WAY 100635 was chosen on the basis of a pilot study confirming its activity against LY 228729.

5MT, LY 228729 and WAY 100635 (Sigma-Aldrich, USA) were dissolved in $0.9 \%$ saline solution and administered s.c. in a constant volume of $1 \mathrm{ml} / \mathrm{kg}$ body weight.

On the test day (PND 42), offspring were brought into the laboratory and allowed to acclimate at least $60 \mathrm{~min}$ prior of the experimental sessions. Each test was carried out on different groups of rats except that for open field and forced swim tests. The experiments were performed into a sound isolated dimly illuminated chamber between 09:00 and 14:00 h in April. Animal performance was recorded on a videotape placed in an adjacent room and analyzed by an experimenter unaware of the different treatments. The devices were thoroughly cleaned with ethanol solution $(10 \%, \mathrm{v} / \mathrm{v})$ before the introduction of each animal to ensure that a particular rat's behaviour was affected by the detection of other rat scents. The experiments were in accordance with the regulations of the Committee for Use of Experimental Animals of the University of Palermo.

\subsection{Elevated plus-maze test}

The elevated plus-maze was made from dark-grey PVC and consisted of a plus-shaped platform, elevated to a height of $70 \mathrm{~cm}$ above the floor. Two of the opposing arms $(50 \mathrm{~cm} \times 10 \mathrm{~cm})$ were closed by 40 -cm-high side and end-walls (closed arms), whereas the two other arms had no walls (open arms). All four arms were connected at the centre by a $10 \mathrm{~cm} \times 10 \mathrm{~cm}$ platform [61]. At the beginning of each session, the rat was placed into the central area of the maze, facing one of the open arms. During the $5 \mathrm{~min}$ exposure, the number of entries in the open and closed arms, and the time spent on the open and closed arms were recorded. An entry was scored when all the four paws entered into each single arm.

\subsection{Open field test}

Motor activity was measured with a contrast-sensitive, video-tracking system, the Opto-Varimex (Columbus Instruments, USA). This apparatus was a square box, $44 \mathrm{~cm}$ wide, $44 \mathrm{~cm}$ long and $20 \mathrm{~cm}$ high, whose perpendicular sides had 15 infrared emitters. Each beam was separated from the next one by a distance of $2.54 \mathrm{~cm}$. The apparatus produces a qualitative mapping of motor patterns, measuring different parameters simultaneously: total distance travelled, rearing frequency, number of transitions from peripheral to central squares of the arena, and amount of time spent on the central areas. Each experimental session lasted $5 \mathrm{~min}$; the animal motor patterns were recorded $1 \mathrm{~min}$ after the rats were placed in the box, and displayed on a PC. 


\subsection{Forced swim test}

Rats were tested immediately after the open field test. Briefly, the animals were given a single trial in which they were placed inside a plexiglas cylinder ( $40 \mathrm{~cm}$ high, $18 \mathrm{~cm}$ inside diameter) containing 5-61 of clean water, depending on the rat size, maintained at $22 \pm 1{ }^{\circ} \mathrm{C}$, from which they could not escape. The following behavioural patterns were registered on videotapes during the $10 \mathrm{~min}$ of the test session:

- time spent on immobility, defined as floating in the water, making only the movements necessary to keep the head above water;

- time spent on swimming, defined as making active swimming motions and moving around in the cylinder;

- time spent on struggling, defined as strongly moving all four limbs with the front paws breaking the water surface or scratching the tank well and diving.

At the end of the 10 min-session, rats were removed and dried under a lamp.

\subsection{Statistics}

Statistical analysis of the data from the elevated plus-maze test was carried out using two-tailed Student's $t$-test for paired data with Bonferroni correction $(\alpha=0.001)$. The data from open field and forced swim tests were analyzed using two-tailed Student's $t$-test for paired data, with Boferroni correction $(\alpha=0.001)$ and the analysis of variance (ANOVA) followed by a post hoc Tukey's test. Differences were considered statistically significant if $p<0.05$.

\section{Results}

\subsection{Elevated plus-maze test}

Rats were tested in the elevated plus-maze in order to evaluate the effects of the perinatal exposure to 5MT on anxiety-like behaviour expressed as preference for the open arms with respect to the closed arms of the maze. Data have been analyzed using a two-tailed Student' $t$-test performed on the percentage of the number of entries in the open arms/the number of entries in the open and closed arms, and as percentage of the amount of time spent on the open arms/the amount of time spent on the open and closed arms.

Our data indicate that perinatal exposure to 5MT induced a significant increase in the preference for the open arms as shown by higher percentage of entries in the open arms/total entries in the open and closed arms $(t=5.2394$, d.f. $=65.136, p$ value $=0.000123)$ and by higher percentage of time spent on the open arms/total time spent on open and closed arms $(t=4.6493$, d.f. $=60.365, p$-value $=0.000375)$, with respect to perinatally vehicle-exposed rats (Fig. 1).

\subsection{Open field test}

Data from the experiments in the open field have been analyzed in order to verify: at first, whether perinatal exposure to 5MT-induced differences in the measured parameters: total distance travelled, rearing frequency, number of transitions and amount of time spent on the central areas of the arena compared to perinatally vehicle-exposed rats; secondly, to evaluate the effects of the acute administration of the selective 5-HT1A agonist LY 228729 and its co-administration with the selective 5-HT1A antagonist WAY 100635 on the above mentioned parameters in perinatally vehicle- and 5MT-exposed rats.
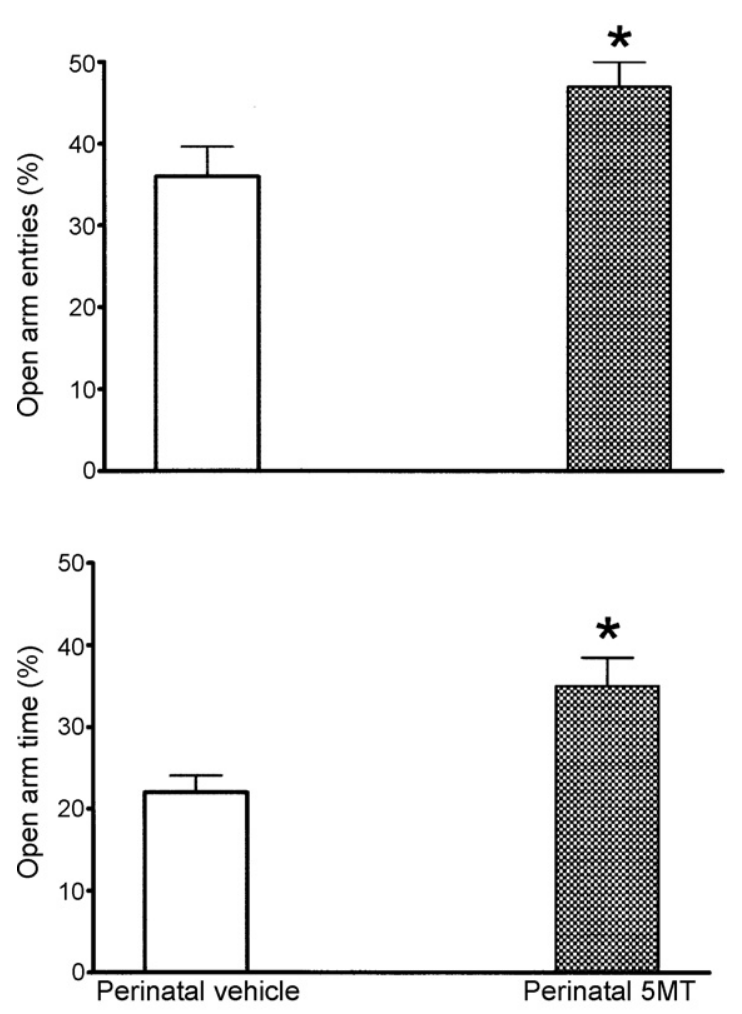

Fig. 1. Elevated plus-maze test. Effects of perinatal 5MT exposure on percentage of entries and time spent on the open arms. Each value represents the mean \pm S.D. of eight rats. ${ }^{*} P<0.05$ vs. perinatally vehicle- exposed rats.

The analysis from a two-tailed Student's $t$-test shows that perinatal exposure to $5 \mathrm{MT}$ reduced total distance travelled $(t=-12.9807$, d.f. $=38.074, p$-value $=1.476 \mathrm{E}-15)$ and rearing frequency $(t=-4.3803$, d.f. $=61.608, p$-value $=4.684 \mathrm{E}-05)$, increased the amount of time spent on the centre of the arena $(t=-1.3684$, d.f. $=58.396, p$-value $=0.0176)$, compared to perinatally vehicle-exposed offspring, while no significant effect was observed in the number of transitions $(t=2.2984$, d.f. $=61.243, p$-value $=0.199)$ in the centre of the arena (Fig. 2).

The effects of postnatal acute treatments with LY 228729, WAY 100635 and LY 228729 + WAY 100635 on the behavioural patterns in the open field were analyzed with a two-way ANOVA in perinatally vehicle- and 5MT-exposed rats (Table 1A). The statistical analysis showed a significant effect of the perinatal exposure to 5MT and of the postnatal acute treatments with LY 228729, WAY 100635 and LY 228729 + WAY 100635 as dependent variables, and of their interaction concerning total distance travelled and amount of time spent on the central squares of the arena. Regarding rearing frequency and number of transitions in the central areas of the open field, the interaction between perinatal treatment with 5MT and postnatal acute treatments with LY 228729, WAY 100635 and LY 228729+WAY 100635 was not significant. Therefore, a one-way ANOVA was performed on the variable postnatal acute treatments with LY 228729, WAY 100635 and LY 228729+ WAY 100635 within both perinatal vehicle- and 5MT groups for rearing frequency and number of transitions in the centre of the arena (Table 1B). A post hoc Tukey's test was then performed in order to underlie which 

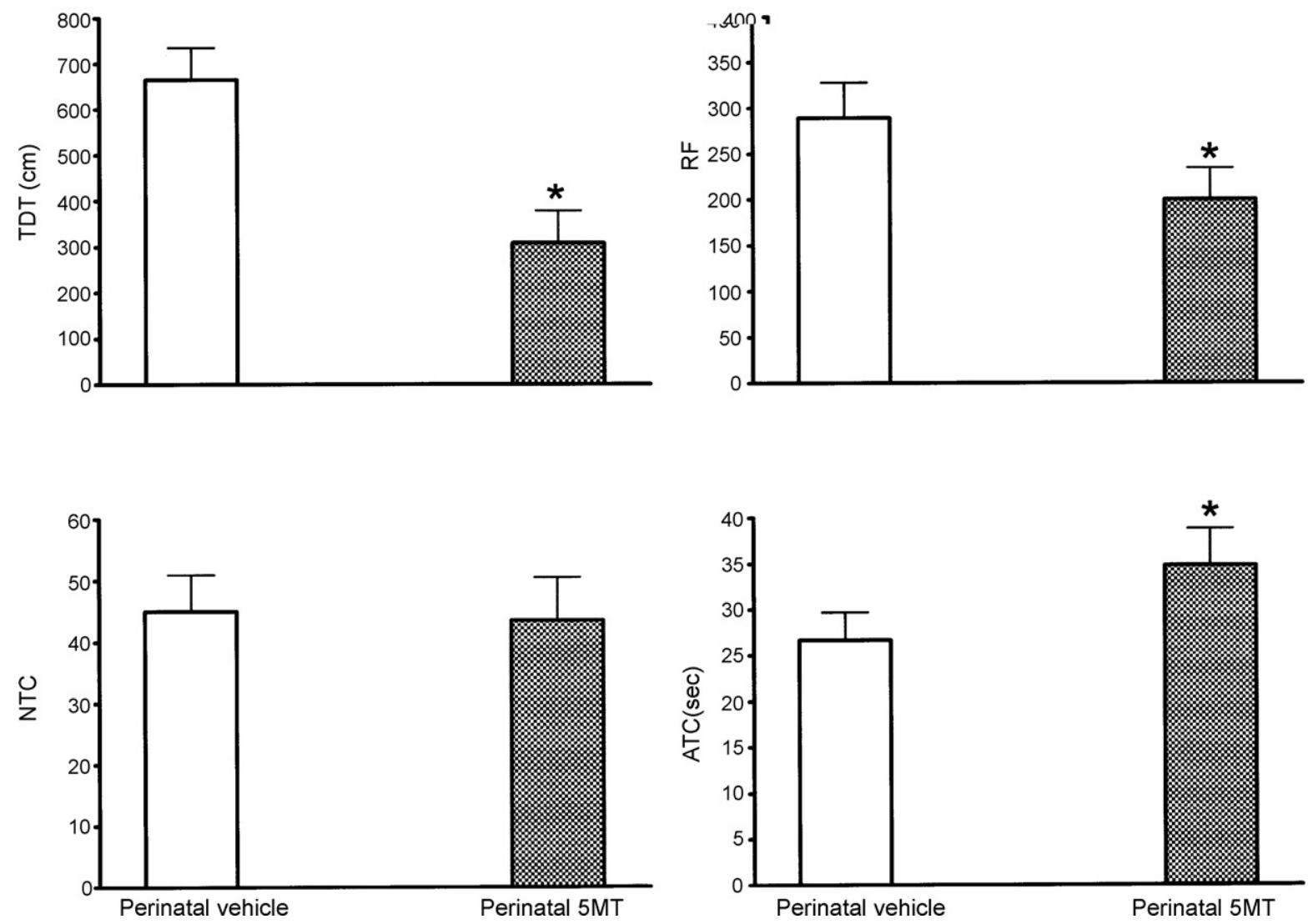

Fig. 2. Open field test. Effects of perinatal 5MT exposure on the total distance travelled (TDT), rearing frequency (RF), number of transitions (NTC) and amount of time spent (ATC) in the central areas of the arena. Each value represents the mean \pm S.D. of eight rats. ${ }^{*} P<0.05$ vs. perinatally vehicle- exposed rats.

drug was significantly effective on the parameters observed in the perinatally vehicle- and in the perinatally 5MT experimental groups. Our results show that the acute treatment with LY 228729 was effective in increasing total distance travelled in perinatally vehicle-exposed rats, and in decreasing rearing frequency, number of transitions and amount of time spent on the centre of the arena in both perinatally vehicle- and 5MTexposed rats. When LY 228729 was administered together with the selective 5-HT1A antagonist WAY 100635, the observed LY 228729-induced effects were completely abolished in both perinatally vehicle- and 5MT-exposed rats. When administered alone, WAY 100635 did not exert any effect on the behavioural patterns in the open field in both experimental groups (Table 2).

\subsection{Forced swim test}

The effects of perinatal 5MT exposure on immobility, swimming and struggling have been analyzed by a two-tailed Student' $t$-test. Our data indicate that perinatally 5MT-exposed rats showed a significant reduction in immobility $(t=-4.4766$, d.f. $=61.026, p$-value $=0.000522)$ and an increase in swim$\operatorname{ming}(t=-3.846$, d.f. $=58.123, p$-value $=0.008076)$, compared to perinatally vehicle-treated rats. No differences in struggling have been observed between the two experimental groups $(t=-1.537$, d.f. $=59.613, p$-value $=0.177)($ Fig. 3).

The effects of the postnatal acute administration of LY 228729, WAY 100635 and LY $228729+$ WAY 100635 in both perinatally vehicle- and 5MT-exposed rats have been analyzed with a two-way ANOVA, respectively performed on immobility, swimming and struggling as dependent variables, and perinatal exposure to 5MT and postnatal acute treatments with LY 228729, WAY 100635 and LY 228729+WAY 228729 as independent variables. Data indicate that the factors perinatal exposure to 5MT and postnatal acute treatments with LY 228729, WAY 100635 and LY 228729+WAY 100635 were significant for immobility and swimming and not for struggling. The interaction between perinatal exposure to 5MT and postnatal acute treatments with LY 228729, WAY 100635 and LY 228729 + WAY 100635 was significant for immobility and swimming, but not for struggling (Table 3).

Results from a post hoc Tukey's test show that LY 228729 reduced immobility and increased swimming in both perinatally vehicle- and 5MT-exposed rats while WAY 100635 was ineffective, when compared to respective controls. When administered together with LY 228729, WAY 100635 was able to reverse the effects exerted by the selective 5-HT1A receptor agonist in both perinatally vehicle- and 5MT-exposed rats (Table 4).

\section{Discussion}

The current study was undertaken to investigate the effects of the perinatal exposure to $5 \mathrm{MT}$ on behavioural-stress reactivity and on the functional response of 5-HT1A receptors in adolescent rats evaluating different stress-related behavioural patterns. 
Table 1A

Open field test: results of a two-way ANOVA performed on total distance travelled (TDT), rearing frequency (RF), number of transitions in the centre (NTC) and amount of time spent on the centre (ATC) of the arena, as dependent variables and perinatal exposure (5MT) (1) and acute postnatal treatment (LY 228729, WAY 100635, LY 228729 + WAY 100635) (2), as independent variables

\begin{tabular}{|c|c|c|c|}
\hline Effects & d.f. & $F$ & $P$ level \\
\hline \multicolumn{4}{|l|}{ TDT } \\
\hline 1 & 1 & 315.957 & $<2.2 \mathrm{E}-16^{* * * *}$ \\
\hline 2 & 3 & 14.963 & $2.861 \mathrm{E}-07^{* *}$ \\
\hline $1: 2$ & 3 & 5.123 & $0.003346^{* * *}$ \\
\hline Residuals & 56 & & \\
\hline Total & 63 & & \\
\hline \multicolumn{4}{|l|}{ RF } \\
\hline 1 & 1 & 52.8612 & $1.236 \mathrm{E}-09^{* * *}$ \\
\hline 2 & 3 & 37.3014 & $2.213 \mathrm{E}-13^{* * *}$ \\
\hline $1: 2$ & 3 & 0.9686 & 0.4141 \\
\hline Residuals & 56 & & \\
\hline Total & 63 & & \\
\hline \multicolumn{4}{|l|}{ NTC } \\
\hline 1 & 1 & 6.2422 & $0.01544^{*}$ \\
\hline 2 & 3 & 56.637 & $<2 \mathrm{E}-16^{* * * *}$ \\
\hline $1: 2$ & 3 & 1.2138 & 0.3132 \\
\hline Residuals & 56 & & \\
\hline Total & 63 & & \\
\hline \multicolumn{4}{|l|}{ ATC } \\
\hline 1 & 1 & 9.073 & $0.003889^{* *}$ \\
\hline 2 & 3 & 76.097 & $2.2 \mathrm{E}-16^{* * *}$ \\
\hline $1: 2$ & 3 & 5.366 & $0.003346^{* *}$ \\
\hline Residuals & 56 & & \\
\hline Total & & & \\
\hline
\end{tabular}

The results indicate that perinatal exposure to 5MT is effective in decreasing anxiety-like behaviour and does not change the behavioural patterns induced by the activation of 5-HT1A receptors.

When tested in the elevated plus-maze, perinatally 5MTexposed rats showed an increase in the percentage of entries and time spent on the open arms, compared to perinatally vehicle-exposed rats. The elevated plus-maze represents a valid behavioural model to study the emotional response of the ani-
Table 1B

Open field test: results of a one-way ANOVA performed on rearing frequency (RF) and number of transitions in the centre of the arena (NTC) as dependent variables and acute postnatal treatment (LY 228729, WAY 100635, LY 228729 + WAY 100635) (1), as independent variable, in perinatally vehicle- and in perinatally $5 \mathrm{MT}$-exposed groups

\begin{tabular}{lccc}
\hline Effects & d.f. & $F$ & $P$ level \\
\hline RF & & & \\
Perinatally vehicle-exposed group & & \\
$\quad$ Residuals & 3 & 9.6515 & $0.0001535^{*}$ \\
$\quad$ Total & 31 & & \\
Perinatally 5MT-exposed group & & $2.901 \mathrm{E}-12^{*}$ \\
1 & 3 & 59.458 & \\
Residuals & 28 & & \\
Total & 31 & & \\
& & & \\
NTC & & & \\
Perinatally vehicle-exposed group & & \\
1 & 3 & 17.002 & \\
Residuals & 28 & & \\
Total & 31 & & \\
Perinatally 5MT-exposed group & & \\
1 & 3 & 78.832 & \\
Residuals & 28 & & \\
Total & 31 & & \\
\hline$*$ & & & \\
$P<0.001$. & & & \\
& & &
\end{tabular}

mals. An avoidance or a preference for the open arms are respectively ascribed to a rise or a reduction in state anxiety $[19,51,52]$. Indeed, anxiogenic drugs increase the behavioural avoidance for the open arms, while anxiolytic drugs reduce it [54]. Therefore, the higher values in the percentage of entries and time spent on the open arms of the elevated plus-maze, observed in perinatally 5MT-exposed rats, suggest a lower emotionality in these animals with respect to perinatally vehicle-exposed rats.

In the open field test perinatally 5MT-exposed rats displayed a decrease in behavioural reactivity, as shown by reduced total distance travelled and rearing frequency, while time spent on the central areas was increased. When rats are tested for the first time in the open field, they commonly show a great behavioural reactivity. Both total distance travelled and rearing frequency, two patterns interpreted as an initial escape behaviour, are increased $[5,6,62]$. At the same time, rats exhibit a lower explorative activ-

Table 2

Open field test: effects of acute treatments with LY 228729, WAY 100635, LY 228729 + WAY 100635 on total distance travelled (TDT), rearing frequency (RF), number of transition in the centre (NTC) and amount of time spent on the centre (ATC) of the arena in perinatally vehicle- and in perinatally 5MT-exposed rats

\begin{tabular}{|c|c|c|c|c|c|}
\hline Perinatal exposure & Postnatal treatment & TDT & $\mathrm{RF}$ & NTC & ATC \\
\hline Vehicle & $\begin{array}{l}\text { Saline } \\
\text { LY228729 } \\
\text { WAY100635 } \\
\text { LY } 228729+\text { WAY } 100635\end{array}$ & $\begin{aligned} 664.5 & \pm 39.1 \\
897.7 & \pm 49.1 \mathrm{a} \\
622.5 & \pm 38.9 \\
631 & \pm 30.3 \mathrm{~b}\end{aligned}$ & $\begin{array}{l}289.8 \pm 34.6 \\
145.2 \pm 12.6 \mathrm{a} \\
263.3 \pm 24.4 \\
251.4 \pm 9.5 b\end{array}$ & $\begin{aligned} 44.4 & \pm 7.6 \\
11.7 & \pm 4.7 \mathrm{a} \\
47.3 & \pm 6.3 \\
48 & \pm 3.2 \mathrm{~b}\end{aligned}$ & $\begin{aligned} 26.7 & \pm 2.4 \\
4.7 & \pm 3.0 \mathrm{a} \\
25.6 & \pm 3.8 \\
27.7 & \pm 1.3 \mathrm{~b}\end{aligned}$ \\
\hline $5 \mathrm{MT}$ & $\begin{array}{l}\text { Saline } \\
\text { LY } 228729 \\
\text { WAY } 100635 \\
\text { LY } 228729 \text { + WAY } 100635\end{array}$ & $\begin{aligned} 307.7 & \pm 19.8 \\
374 & \pm 8.6 \\
298.6 & \pm 22.4 \\
310.8 & \pm 9.7\end{aligned}$ & $\begin{aligned} 197.6 & \pm 10.6 \\
37.3 & \pm 2 \mathrm{a} \\
205.5 & \pm 16.34 \\
173.6 & \pm 5.5 \mathrm{~b}\end{aligned}$ & $\begin{aligned} 43.3 & \pm 2.1 \\
4.8 & \pm 0.6 \mathrm{a} \\
48.6 & \pm 2.8 \\
36.2 & \pm 2.5 \mathrm{~b}\end{aligned}$ & $\begin{aligned} 34.8 & \pm 2.1 \\
1.1 & \pm 0.2 \mathrm{a} \\
40.5 & \pm 1.9 \\
31 & \pm 2.1 \mathrm{~b}\end{aligned}$ \\
\hline
\end{tabular}

Each value represents the mean \pm S.E.M. from eight rats. ${ }^{\mathrm{a}} P<0.001$ vs. respective perinatal exposure; ${ }^{\mathrm{b}} P<0.001$ vs. respective acute $L Y 228729$-treated group. The statistical analysis is described in Section 3. 

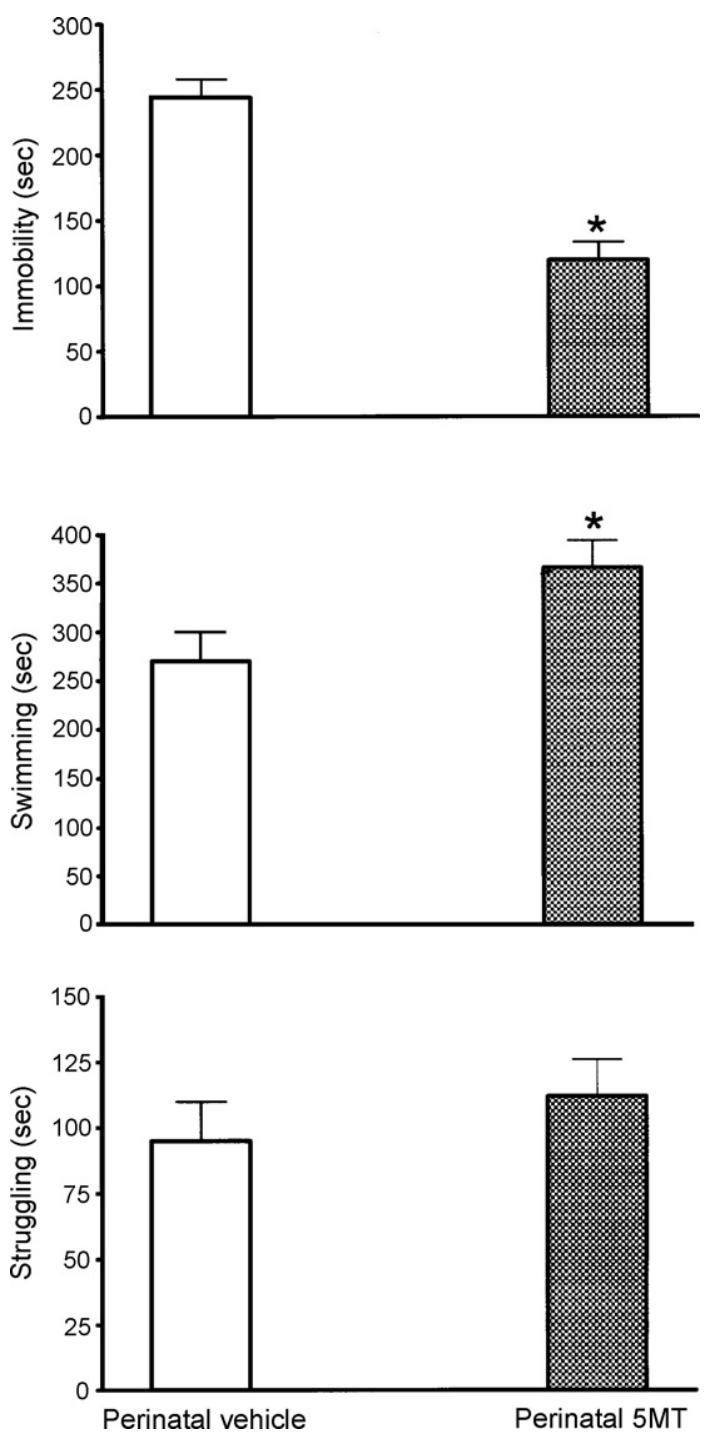

Fig. 3. Forced swim test. Effects of perinatal 5MT exposure on immobility, swimming and struggling time. Each value represents the mean \pm S.D. of eight.

ity in the centre of the arena, reflecting an avoidance of an anxiogenic environment $[39,59]$. Conversely, rats with low emotionality or treated with anxiolytic drugs, show a decrease in total distance travelled and rearing frequency, and a preference for the
Table 3

Forced swim test: results of a two-way ANOVA performed on immobility, swimming and struggling as dependent variables, and perinatal exposure (5MT) (1) and acute postnatal treatment (LY 228729, WAY 100635, LY 228729+ WAY 100635) (2), as independent variables

\begin{tabular}{lrrl}
\hline Effects & d.f. & \multicolumn{1}{l}{$F$} & $P$ level \\
\hline Immobility & & & \\
1 & 1 & 2134.543 & $2.2 \mathrm{E}-16^{*}$ \\
2 & 3 & 455.919 & $2.2 \mathrm{E} 16^{*}$ \\
$1: 2$ & 3 & 37.555 & $1.1955 \mathrm{E}-13^{*}$ \\
$\quad$ Residuals & 56 & & \\
$\quad$ Total & 63 & & \\
Swimming & & & \\
1 & 1 & 567.405 & $2.2 \mathrm{E} 16^{*}$ \\
2 & 3 & 175.268 & $2.2 \mathrm{E}-16^{*}$ \\
$1: 2$ & 3 & 11.203 & \\
Residuals & 56 & & \\
Total & 63 & & \\
Struggling & & & $0.417 \mathrm{E}-06^{*}$ \\
1 & 1 & 1.755 & 0.2135 \\
2 & 3 & 0.869 & \\
$1: 2$ & 3 & 1.454 & \\
Residuals & 56 & & \\
Total & 63 & & \\
\hline
\end{tabular}

${ }^{*} P \leq 0.001$.

centre of the arena [12,21]. Thus, the results from the open field appear to be consistent with the effects observed in the elevated plus-maze, confirming a reduced emotional response during non-aversive behavioural tasks in perinatally 5MT-exposed rats.

When perinatally 5MT-exposed offspring were tested in a single session of the forced swim test, they displayed a strong decrease in immobility, an increase in swimming, and no modifications in struggling, compared to perinatally vehicle-exposed rats. Previous researches showed that animals from the low anxiety-related behavioural line, spend less time in immobility and more time in swimming than the high-anxiety related behavioural line, and that a significant correlation exists between the main plus-maze parameters and the scores in the forced swim test $[11,45]$. Therefore, the decrease in immobility and the increase in swimming recorded in perinatally 5MT-exposed rats would indicate a lower sensitivity of these rats to stressful stimuli such as the forced swim. However, the possibility

Table 4

Forced swim test: effects of acute treatments with LY 228729, WAY 100635, LY 228729 + WAY 100635 on immobility, swimming and struggling in perinatally vehicle- and in perinatally $5 \mathrm{MT}$-exposed rats

\begin{tabular}{|c|c|c|c|c|}
\hline Perinatal exposure & Postnatal treatment & Immobility & Swimming & Struggling \\
\hline Vehicle & $\begin{array}{l}\text { Saline } \\
\text { LY } 228729 \\
\text { WAY } 100635 \\
\text { LY } 228729+\text { WAY } 100635\end{array}$ & $\begin{array}{l}245 \pm 14 \\
115 \pm 12 \mathrm{a} \\
260 \pm 13 \mathrm{~b} \\
250 \pm 13.7 \mathrm{~b}\end{array}$ & $\begin{array}{l}265 \pm 30 \\
400 \pm 31 a \\
240 \pm 28 b \\
250 \pm 29.5 b\end{array}$ & $\begin{array}{r}94 \pm 9 \\
80 \pm 8 \\
100 \pm 7 \\
100 \pm 8\end{array}$ \\
\hline $5 \mathrm{MT}$ & $\begin{array}{l}\text { Saline } \\
\text { LY } 228729 \\
\text { WAY } 100635 \\
\text { LY } 228729+\text { WAY } 100635\end{array}$ & $\begin{aligned} 120 & \pm 13.5 \\
35 & \pm 11.5 \mathrm{a} \\
130 & \pm 14 \mathrm{~b} \\
135 & \pm 12.8 \mathrm{~b}\end{aligned}$ & $\begin{array}{l}365 \pm 29 \\
475 \pm 30 \mathrm{a} \\
355 \pm 31 \mathrm{~b} \\
360 \pm 30.2 \mathrm{~b}\end{array}$ & $\begin{aligned} 115 & \pm 7 \\
90 & \pm 6 \\
115 & \pm 7 \\
105 & \pm 6\end{aligned}$ \\
\hline
\end{tabular}

Each value represents the mean \pm S.E.M. from eight rats. ${ }^{\mathrm{a}} P<0.001$ vs. respective perinatal exposure; ${ }^{\mathrm{b}} P<0.001$ vs. respective acute LY228729-treated group. The statistical analysis is described in Section 3. 
that perinatal exposure to 5MT could exert a more complex action on sensory/motor patterns, cannot be excluded. Indeed, an hyper-responsiveness to sensory stimuli, more vigorous movements during motor skill evaluations, and an increase in escape behaviour following tactile stimulation, as reported in a rat hyper-serotonergic model [38], might contribute to the reduction in immobility and to the increase in swimming observed in this study in perinatally 5MT-exposed rats. The lack of effect on struggling by perinatal exposure to 5MT is consistent with reports showing that this parameter is not influenced by manipulations of the serotonergic system. Indeed, struggling is commonly recognized as a behaviour which depends on the activation of noradrenergic transmission [23].

Several researches indicate that the central serotonergic system is involved in the patho-physiology and in the treatment of anxiety [8]. Preclinical models of anxiety show that drugs able to reduce serotonergic function decrease fearful behaviour and display anxiolytic-like effects in rats [32]. The effects of serotonin on the physiological and behavioural responses to stressful stimuli seem to be dependent on the receptor subtype where it acts upon. Among the multiple subtypes of receptors for serotonin present in the brain, 5-HT1A receptor plays a major role in the regulation of serotonin neuronal activity $[3,36]$ and it is a critical mediator of the neuroendocrine responses to stress [8,30]. 5-HT1A receptors are located both postsynaptically and presinaptically $[29,31]$, the latter mediating the anxiolytic effects $[24,25,47]$.

Moreover, 5-HT1A receptor is the earliest serotonin receptor subtype which appears in the developing brain, with a prenatal peak, both in humans and in rodents [9,50]. The expression of 5-HT1A receptors is initially localised around the serotonergic cell body and gradually shifts to the dendrites during postnatal development after the neurons have matured [50].

Pharmacological manipulations of 5-HT1A receptors in utero and during early postnatal life induce long-term developmental consequences on 5-HT1A receptor responses and serotonergic neurotransmission $[44,48,56,62,63,67]$. In particular, prenatal over-stimulation of 5-HT1A receptors with 5MT reduces the expression of this receptor subtype in neonatal rat offspring [43]. A large receptor reserve exists for presynaptic, but not for postsynaptic 5-HT1A receptors $[17,49,70]$. Thus, it is likely that perinatal 5MT exposure may reduce anxiety-like behaviour in adolescent rats throughout the mediation, at least in part, of presynaptic 5-HT1A receptors, which would display a predominant density with respect to postsynaptic 5-HT1A receptors in the serotonergic neuron, as a consequence of the early pharmacological manipulation.

When the functional response of 5-HT1A receptors was investigated in perinatally vehicle-exposed rats, the selective 5HT1A receptor agonist LY 228729 [26,28] induced an increase in locomotor activity, a decrease in rearing frequency, and an increase in peripheral activity (random circling) in the open field test, and a decrease in immobility and an increase in swimming in the forced swim test, as a consequence of a direct stimulation of 5-HT1A receptors [22,23,33]. The administration of the selective 5-HT1A receptor antagonist WAY 100635 was ineffective. The co-administration of LY 228729 and WAY
100635 abolished the effects exerted by LY 228729 in both tests. In perinatally 5MT-exposed rats, LY 228729 administration, and its association with WAY 100635, produced similar effects than in perinatally vehicle-exposed rats, both in the forced swim and in the open field tests, except for locomotor activity. These results suggest that, although perinatal exposure to 5MT reduces 5-HT1A receptor density in neonatal offspring [43], it does not change the specific behavioural patterns induced by the activation of 5-HT1A receptors in adolescent rats. The ineffectiveness of LY 228729 in modifying struggling, in both perinatally vehicle- and 5MT-exposed rats, represents a further support to the selective efficacy of this compound in affecting behavioural patterns which reflect a specific activation of the serotonergic system.

With regard to locomotor activity in the open field test, LY 228729 was effective in increasing total distance travelled only in perinatally vehicle-exposed rats. Indeed, it is largely reported that stimulation of postsynaptic 5-HT1A receptors by selective agonists is correlated with an increase in locomotor activity, likely through an increase in noradrenalin release mainly in the hippocampus [58]. In our study, the effect of LY 228729 on locomotor activity was selectively abolished by WAY 100635. Currently, we have not sufficient data to explain the ineffectiveness of LY 228729 in increasing locomotor activity in rats perinatally exposed to 5MT. However, we can speculate that perinatal stimulation of 5-HT1A receptors by 5MT may induce a reduction in those postsynaptic receptors, whose stimulation is required to increase noradrenalin release and produce an increase in locomotor activity [58]. Nevertheless, we cannot exclude that an involvement of other neural mechanisms may underlie the different effect observed.

In conclusion, the present study showed that perinatal exposure to 5MT decreases behavioural-stress reactivity in adolescent male rats. The mechanism underling 5MT effects remains to be further elucidated. Currently, we favour the hypothesis that, at least in part, an imbalance between pre- and postsynaptic 5-HT1A receptors, as a result of the perinatal 5MT exposure, may be responsible for the present results. Moreover, this study shows that perinatal exposure to 5MT does not deteriorate the functional response of 5-HT1A receptors to selective agonist and antagonist compounds.

\section{Acknowledgements}

The authors would like to thank PhD student M. Daniele for statistical assistance and Mr. F. Beninati for excellent technical assistance. This research was supported by MIUR.

\section{References}

[1] Aghajanian GK, Sanders-Bush E. Serotonin. In: Davis KL, Charney D, Coyle JT, Nemeroff C, editors. Psychopharmacology: the fifth generation of progress. New York: Raven Press; 2002. p. 15-34.

[2] Aitken AR, Tork I. Early development of serotonin-containing neurons and pathways as seen in whole-mount preparations of the fetal rat brain. J Comp Neurol 1988;274:32-47. 
[3] Albert PR, Lembo P, Storring JM, Charest A, Saucier C. The 5-HT1A receptor: signaling, desensitization, and gene transcription. Neuropsychopharmacology 1996;14:19-25.

[4] Amaral DG, Corbett BA. The amygdala, autism and anxiety. In: Novartis foundation symposium, vol 251. 2003. p. 177-97.

[5] Archer J. Tests for emotionality in rats and mice: a review. Anim Behav 1973;21:205-35.

[6] Aulich D. Escape versus exploratory activity: an interpretation of rats' behaviour in the open field and a light-dark preference test. Behav Proc 1976;1:153-64.

[7] Baldwin D, Rudge S. The role of serotonin in depression and anxiety. Int J Clin Psychopharmacol 1995;9:41-5.

[8] Barnes NM, Sharp T. A review of central 5-HT receptors and their function. Neuropharmacology 1999;38:1083-152.

[9] Bar-Peled O, Gross-Iseroff R, Ben-Hur H, Hoskins I, Groner Y, Bigeon A. Fetal human brain exhibits a prenatal peak in density of serotonin $5-\mathrm{HT}_{1 \mathrm{~A}}$ receptors. Neurosci Lett 1991;127:173-6.

[10] Benvenga MJ, Leander JD. Antidepressant-like effect of LY 228729 as measured in the rodent forced swim paradigm. Eur $\mathrm{J}$ Pharmacol 1993;239:249-52.

[11] Bohus B, Benus RF, Fokkema DS, Koolhaas JM, Nyakas C, van Dortmerssen GA, et al. Neuroendocrine states and behavioural and physiological stress responses. Prog Brain Res 1987;72:57-70.

[12] Cannizzaro C, Martire M, Cannizzaro E, Provenzano G, Gagliano M, Carollo A, et al. Long-lasting handling affects behavioural reactivity in adult rats of both sexes prenatally exposed to diazepam. Brain Res 2001;904:225-33.

[13] Cannizzaro C, Martire M, Cannizzaro E, Monastero R, Gagliano M, Mineo A, et al. Effects of 8-OH-DPAT on open field performance of young and aged rats prenatally exposed to diazepam: a tool to reveal 5-HT1A receptor function. Eur Neuropsychopharmacol 2003;13:209-17.

[14] Cervo L, Mocaer E, Bertaglia A, Samanin R. Roles of 5-HT $1 \mathrm{~A}$ receptors in the dorsal raphe and dorsal hippocampus in anxiety assessed by the behavioural effects of 8-OH-DPAT and S 15535 in a modified Geller-Seifter conflict model. Neuropharmacology 2000;39:1037-43.

[15] Chapillon P, Patin V, Roy V, Vincent A, Caston J. Effects of pre- and postnatal stimulation on developmental, emotional and cognitive aspects of rodents: a review. Dev Psychobiol 2002;41:373-87.

[16] Corradetti R, Le Poul E, Laaris N, Hamon M, Lanfumey L. Electrophysiological effects of $N$-(2-(4-(2-methoxyphenyl)-1-piperazinyl) ethyl)- $N$-(2-pyridinyl) cyclohexane carboxamide (WAY 100635) on dorsal raphe serotonergic neurons and CA1 hippocampal pyramidal cells in vitro. J Pharmacol Exp Ther 1996;278:679-88.

[17] Cox RF, Meller E, Wasczak BL. Electrophysiological evidence for a large receptor reserve for inhibition of dorsal raphe neuronal firing by $5-\mathrm{HT}_{1 \mathrm{~A}}$ agonists. Synapse 1993;14:297-304.

[18] Dal-Zotto S, Martì O, Armario A. Influence of single or repeated experience of rats with forced swimming on behavioural and physiological responses to the stressor. Behav Brain Res 2000;114:175-81.

[19] Dawson GR, Tricklebank MD. Use of the elevated plus-maze in the search for novel anxiolytic agents. Trend Pharmacol Sci 1995;16:33-6.

[20] De La Garza R, Cunningham KA. The effects of the 5-hydroxytriptamine 1A agonist 8 -hydroxy 2 -(di- $n$-propylamino) tetralin on spontaneous activity, cocaine-induced hyperactivity and behavioural sensitization: a microanalysis of locomotor activity. J Pharmacol Exp Ther 2000;292:610-7.

[21] Denemberg VH. Open field behaviour in the rat: what does it mean. Ann NY Acad Sci 1969;159:852-9.

[22] Detke MJ, Wieland J, Lucki I. Blockade of the antidepressant-like effects of 8-OH-DPAT, buspirone and desipramine in the rat forced swim test by 5-HT receptor antagonists. Psychopharmacology 1995;119:47-54.

[23] Detke MJ, Rickels M, Lucki I. Active behaviours in the forced swimming test differently produced by serotonergic and noradrenergic antidepressants. Psychopharmacolgy 1995;121:66-72.

[24] De Vry J. 5-HT1A receptor ligands: recent developments and controversial issues. Psychopharmacology 1995;121:1-26.

[25] De Vry J, Schreiber R, Melon C, Dalmus M, Jentzsch KR. 5-HT 1 A receptors are differentially involved in the anxiolytic- and antidepressant-like effects of 8-OH-DPAT and fluoxetine in the rat. Eur Neuropsychopharmacol 2004;14:487-95.

[26] Flaugh ME, Muller DL, Fuller RW, Mason NR. 6-Substituted 1,3,4,5tetrahydrobenz $[c d]$ indol-4-amines: potent serotonin agonists. J Med Chem 1988;31:1746-53.

[27] Foreman MM, Fuller RJ, Leander DJ, Benvenga MJ, Wong DT, Nelson DL, et al. Preclinical studies on LY 228729: a potent and selective serotonin (1A) agonist. J Pharmacol Exp Ther 1993;267:58-71.

[28] Forster EA, Cliffed IA, Bill DJ, Dover GM, Jones D, Reilly Y, et al. A pharmacological profile of the selective silent 5-HT(1A) receptor antagonist WAY-100635. Eur J Pharmacol 1995;281:81-8.

[29] Glaser T, Devry J. Neurobiology of 5-HT 1A receptors. In: Stahl SM, Gaspar M, Hesselink JM, editors. Serotonine 1A receptors in depression and anxiety. New York: Raven Press; 1992. p. 35-53.

[30] Graeff FG, Guimaraes FS, Andrade GCS, Deakin JFW. Role of 5HT in stress, anxiety and depression. Pharmacol Biochem Behav 1996;54:129-41.

[31] Hamon M. The main feature of central 5-HT1A receptors. In: Baumgarten M, Gothert M, editors. Serotoninergic neurons and 5-HT receptors in the CNS. Handbook of experimental pharmacology. Berlin: Springer; 1997. p. 239-68.

[32] Handley SL. 5-hydroxytryptamine pathways in anxiety and its treatment. Pharmacol Ther 1995;66:103-48.

[33] Heal DJ, Luscombe GP, Martin KF. Pharmacological identification of 5HT receptor subtypes using behavioural models. In: Marsden CD, Heal DJ, editors. Central serotonin receptors and psychotropic drugs. London: Blackwell Scientific Publication; 1992. p. 56-99.

[34] Heisler LK, Chu H-M, Brennan TJ, Danao JA, Bajwa P, Parsons LH, et al. Elevated anxiety and antidepressant-like responses in serotonin 5-HT1A receptor mutant mice. Proc Nat Acad Sci 1998;95:15049-54.

[35] Hillegaart V, Wadenberg ML, Ahlenius S. Effects of 8-OH-DPAT on motor activity in the rat. Pharmacol Biochem Behav 1989;32:797-800.

[36] Hjorth S, Magnusson T. The 5-HT(1A) receptor agonist, 8-OH-DPAT, preferentially activates cell body 5 -HT autoreceptors in rat brain in vivo. Naunyn-Schmiedeberg's Arch Pharmacol 1988;338:463-71.

[37] Hogg S. A review of the validity and variability of the elevated plusmaze as an animal model of anxiety. Pharmacol Biochem Behav 1996;54: 21-30.

[38] Kahne D, Tudorica A, Borella A, Shapiro L, Johnstone F, Huang W, et al. Behavioral and magnetic resonance spectroscopic studies in the rat hyperserotonemic model of autism. Physiol Behav 2002;75:403-10.

[39] Kelly AE. Locomotor activity and exploration. In: Sahgal, editor. Behavioural neuroscience. A practical approach, vol. 2A. Oxford: Oxford Press; 1993. p. 1-21.

[40] Korte MS, De Kloet ER, Buwalda B, Stephan D, Bouman SD, Bohus B. Antisense to the glucocorticoid receptor in hippocampal dentate gyrus reduces immobility in forced swim test. Eur J Pharmacol 1996;301:19-25.

[41] Lauder JM, Krebs H. Serotonin as differentiation signal in early neurogenesis. Dev Neurosci 1978;11:15-30.

[42] Lauder JM. Ontogeny of serotonergic system in the rat: serotonin as a developmental signal. Ann NY Acad Sci 1990;600:297-314.

[43] Lauder JM, Liu J, Grayson DR. In utero exposure to serotonergic drugs alters neonatal expression of 5-HT(1A) receptor transcripts: a quantitative RT-PCR study. Int J Dev Neurosci 2000;18:171-6.

[44] Lidov HG, Molliver ME. Immunohistochemical study of the developmental of serotonergic neurons in the rat CNS. Brain Res Bull 1982;9:559-604.

[45] Liebsch G, Montkowski A, Holsboer F, Landgraf R. Behavioral profiles of two Wistar rat lines selectively bred for high or low anxiety-related behaviour. Behav Brain Res 1998;94:301-10.

[46] Lucki I. The spectrum of behaviors influenced by serotonin. Biol Psychiatry 1998;44:151-62.

[47] Maurel Remy S, Schreiber R, Dalmus M, De Vry J. Somatodendritic 5$\mathrm{HT}_{1 \mathrm{~A}}$ receptors are critically involved in the anxiolytic effects of 8-OHDPAT. Psychopharmacology 1996;125:89-91.

[48] Mazer C, Muneyyirci J, Tahery K, Raio N, Borella A, Whitaker-Azmitia PM. Serotonin depletion during synaptogenesis lead to decreased synaptic density and learning deficit in the adult rat. A model of neurodevelopmental disorders with cognitive deficits. Brain Res Dev 1997;760, 68-64. 
[49] Meller E, Goldstein M, Bohmaker K. Receptor reserve for 5hydroxytriptamine ${ }_{1 \mathrm{~A}}$-mediated inhibition of serotonin synthesis. Possible relationship to anxiolytic properties of 5-hydroxytriptamine ${ }_{1 \mathrm{~A}}$ agonists. Mol Pharmacol 1990;37:231-7.

[50] Patel TD, Zhou FC. Ontogeny of 5-HT1A receptor expression in the developing hippocampus. Dev Brain Res 2005;157:42-57.

[51] Pellow S, Chopin P, File JE, Briley M. Validation of open: closed arm entries in an elevated plus-maze as a measure of anxiety in the rat. J Neurosci Methods 1985;14:149-67.

[52] Pellow S, File SE. Anxiolytic and anxiogenic drug effects on exploratory activity in an elevated plus maze: a novel test of anxiety in the rat. Pharmacol Biochem Behav 1986;24:525-9.

[53] Rènerìc JP, Lucki. Antidepressant behavioural effects by dual inhibition of monoamine reuptake in the rat forced swimming test. Psychpharmacology 1998;136:190-7.

[54] Rodgers RJ, Dalvi A. Anxiety, defence and the elevated plus-maze. Neurosci Behav Rev 1997;21:801-10.

[55] Sanchez C, Mark A. N-Ethoxycarbonyl-2-ethoxy-1,2-dihydroquinoline studies on the role of 5- $\mathrm{HT}_{1 \mathrm{~A}}$ and $5-\mathrm{HT}_{2}$ receptors in mediating foot-shockinduced ultrasonic vocalisation in adult rats. Eur Neuropsychopharmacol 1999;9:287-94.

[56] Shemer AV, Azmitia EC, Whitaker-Azmitia PM. Dose-related effects of prenatal 5-methoxytryptamine (5MT) on development of serotonin terminal density and behaviour. Dev Brain Res 1991;59:59-63.

[57] Spear LP. The adolescent brain and age-related behavioural manifestations. Neurosci Behav Rev 2000;24:417-63.

[58] Suwabe A, Kubota M, Niwa M, Kobayashi K, Kanba S. Effect of a 5-HT1A receptor agonist, flesinoxan, on the extracellular noradrenaline level in the hippocampus and on the locomotor activity of rats. Brain Res 2000;858:393-401.

[59] Vallée M, Mayo W, Dellu F, Moal ML, Simon H, Maccari S. Prenatal stress induces high anxiety and postnatal handling induces low anxiety in adult offspring: correlation with stress-induced corticosterone secretion. J Neurosci 1997;17:2626-36.
[60] Van de Kar LD, Richardson-Morton KD, Rittenhouse PA. Stress: neuroendocrine and pharmacological mechanisms. Methods Archiv Exp Pathol 1991;14:133-73.

[61] Welker WI. Free versus forced exploration of a novel situation by rats. Psychol Rep 1957;3:95-8.

[62] Whitaker-Azmitia PM, Azmitia EC. Auto-regulation of fetal serotonergic neuronal development: role of high affinity serotonin receptors. Neurosci Lett 1986;67:307-31.

[63] Whitaker-Azmitia PM, Lauder JM, Shemer A, Azmitia EC. Postnata changes in serotonin receptors following prenatal alterations in serotonin levels: further evidence for functional fetal serotonin receptors. Dev Brain Res 1987;33:285-9.

[64] Whitaker-Azmitia PM, Shemer AV, Caruso J, Molino L, Azmitia EC. Role of high affinity serotonin receptors in neuronal growth. Ann NY Acad Sci 1990;600:315-33.

[65] Whitaker-Azmitia PM, Druse M, Walker P, Lauder JM. Serotonin as a developmental signal. Behav Brain Res 1995;73:19-29.

[66] Whitaker-Azmitia PM. Serotonin and brain development: role in human developmental disease. Brain Res Bull 2001;56:47985.

[67] Whitaker-Azmitia PM. Behavioural and cellular consequences of increasing serotonergic activity during brain development: a role in autism? Int J Dev Neurosci 2005;23:75-83.

[68] Yan W, Wilson CC, Haring JH. 5-HT(1a) receptor mediates the neurotrophic effect of serotonin on developing dentate granule cells. Dev Brain Res 1997;98:185-90.

[69] Yan W, Wilson CC, Haring JH. Effects of neonatal serotonin depletion on the development of rat dentate granule cells. Dev Brain Res 1997;98:177-84.

[70] Yocca FD, Iben L, Meller E. Lack of apparent receptor reserve at postsynaptic 5-hydroxytryptamine receptors negatively coupled to adenyl cyclase activity in rat hippocampal membranes. Mol Pharmacol 1992;41: 1065-72. 